phys. stat. sol. (a) 35, 281 (1976)

Subject classification: 10.2 and $14.4 ; 22.8$

Laboratcry of Incrganic Chemistry and Materials Science, Department of Chemical Engineering, Twente University of Technology, Enschede ${ }^{1}$ )

\title{
Non-Stoichiometry, Defect Structure, and Dielectric Relaxation in Lanthana-Substituted $\mathrm{SrTiO}_{3}$
}

\author{
By
}

\author{
J. Bouwma, K. J. De VRIES, and A. J. BurgGraAF
}

\begin{abstract}
The non-stoichiometry of the perovskite-type phase $\mathrm{Sr}_{1-\alpha x} \mathrm{La}_{x} \mathrm{TiO}_{3+x(1.5-\alpha)}$ is studied. Pure compounds with $0.9 \leqq \alpha \lesssim 1.5$ could be obtained. This non-stoichiometry can be ascribed to a distribution of $\mathrm{La}(\mathbf{I I I})$ ions and vacancies over $\mathrm{Sr}$ and $\mathrm{Ti}$ sites, which varies with composition. A tetragonal superstructure due to an ordering of defects in layers, is observed for a compound with $x=0.50$ and $\alpha=1.50$. Dielectric relaxations with $0.3 \geqq$ $\lesssim E_{\text {act }} \lesssim 0.4 \mathrm{eV}$ and $\tau_{0}$ of the order of $10^{-12} \mathrm{~s}$ were observed for various compositions. These relaxations are characterized by a narrow distribution of relaxation times and are due to an ionic polarization mechanism.
\end{abstract}

Die Phasenbreite der Phase $\mathrm{Sr}_{1-\alpha x} \mathrm{La}_{x} \mathrm{TiO}_{3+x(1,5-\alpha)}$ des Perowskit-Typs wird untersucht. Es konnten Verbindungen mit $0,9 \leqq \alpha \leqq 1,5$ dargestellt werden. Diese Phasenbreite ist zurückzuführen auf eine variable Verteilung von La(III)-Ionen und Leerstellen über Srund Ti-Plätze, die mit der Zusammensetzung variiert. Eine tetragonale Überstruktur infolge einer Anordnung von Defekten in Schichten, wird für Verbindungen mit $x=0,50$ und $\alpha=1,50$ gefunden. Dielektrische Relaxationen mit $0,3 \leqq E_{\text {aet }} \leqq 0,4 \mathrm{eV}$ und $\tau_{0}$ der Größenordnung $10^{-12} \mathrm{~s}$ werden für mehrere Zusammensetzungen gefunden. Diese Relaxationen werden durch eine enge Verteilung von Relaxationszeiten charakterisiert und werden durch die ionische Polarisierbarkeit verursacht.

\section{Introduction}

The existence of a perovskite $\left(\mathrm{ABO}_{3}\right)$ phase of composition $\mathrm{Sr}_{1-1.5 x} \mathrm{La}_{x} \mathrm{TiO}_{3}$ in the ternary system $\mathrm{SrO}_{-} \mathrm{TiO}_{2}-\mathrm{La}_{2} \mathrm{O}_{3}$ has been reported by Tien and Hummel [1]. Recently, we have found that the non-stoichiometry of this phase is better represented by the formula $\mathrm{Sr}_{1-\alpha x} \mathrm{La}_{x} \mathrm{TiO}_{3+x(1.5-\alpha)}{ }^{2}$ ), in which the parameter $\alpha$ can have values in the range $1.0 \leqq \alpha \lesssim 1.5$ [2]. In order to relate this non-stoichiometry to the defects present we have undertaken an X-ray diffraction study of this phase.

Usually, from intensities of Bragg reflections only very limited information about types and numbers of point defects in a solid can be obtained. However, for a compound with high concentrations of point defects and with a favourable combination of atomic scattering factors, these intensities may provide more details of the defect structure. Due to such favourable conditions, the distribution of cations over available sites could be determined for certain spinels using X-ray intensities [3].

1) P.O. Box 217, Enschede, The Netherlands.

2) Alternatively the composition can be $y=x(1.5-\alpha)$. 
Due to the simple parameter-free cubic structure of the perovskite phase in the system $\mathrm{SrO}_{-} \mathrm{TiO}_{2}-\mathrm{La}_{2} \mathrm{O}_{3}$ and the great number of point defects which must be present in this phase, the types and concentrations of defects might be successfully studied by $\mathrm{X}$-ray diffraction methods in this case. This has been carried out by Tien and Hummel [1] for compounds with $\alpha=1.5$. They concluded that $\mathrm{La}(\mathrm{III})$ ions occupy $\mathrm{Sr}(\mathrm{II})$ sites and that the excess positive charge due to the incorporation of $x \mathrm{I}$ a(III) ions, is compensated by $\frac{1}{2} x \mathrm{Sr}$ site vacancies. It is clear that for compounds with $\alpha<1.5$ additional defects are necessary.

Besides a study of the defect structure of the perovskite phase we have investigated ordering phenomena therein. These have been observed by Tien and Hummel [1] in compounds with high concentrations of La(III) ions, which had been cooled slowly from $1400{ }^{\circ} \mathrm{C}$ to room temperature.

Dielectric relaxations with activation energies between 0.25 and $0.4 \mathrm{eV}$ and relaxation times of $10^{-11}$ to $10^{-13} \mathrm{~s}$ have been reported for lanthana substituted $\mathrm{SrTiO}_{3}(\alpha=1.5)[4,5]$. These relaxations were ascribed to motions of $\mathrm{Ti}(\mathrm{IV})$ ions in oxygen octahedra which were assumed to be distorted by the presence of $\mathrm{La}(\mathrm{III})$ ions and vacancies at Sr sites. In order to study the influence of $x$ and $\alpha$ on this relaxation we have performed some dielectric measurements, too.

\section{Experimental Part}

Samples were prepared from reagent grade $\mathrm{SrCO}_{3}$, $\mathrm{TiO}_{2}$, and $\mathrm{La}_{2} \mathrm{O}_{3}$ powders. Before weighing, the $\mathrm{SrCO}_{3}$ and $\mathrm{TiO}_{2}$ powders were held at $175^{\circ} \mathrm{C}$ for at least $24 \mathrm{~h}$ and the $\mathrm{La}_{2} \mathrm{O}_{3}$ powder was mechanically ground in propanol-2 and then heated at $1200{ }^{\circ} \mathrm{C}$ during at least $5 \mathrm{~h}$. Two cycles of solid state reaction in $\mathrm{Pt}$ crucibles at $1250^{\circ} \mathrm{C}$ during $16 \mathrm{~h}$ followed by grinding in propanol-2 were then performed. Pellets were isostatically pressed $(4000 \mathrm{~atm})$ from the products and these pellets were sintered at $1300{ }^{\circ} \mathrm{C}$ in $\mathrm{Pt}$ crucibles during about $50 \mathrm{~h}$ in an oxygen atmosphere.

Dense samples (porosity less than $2 \%$ ) of grey colour were obtained for compounds with $\alpha=1.5$. For compounds with $\alpha<1.5$ light grey, cream or even white samples were obtained with porosities of about 20 to $30 \%$. Less porous materials with darker colours could be obtained by sintering at higher temperatures, e.g. at $1550{ }^{\circ} \mathrm{C}$ in air, during $40 \mathrm{~h}$.

Overall chemical compositions of the samples were determined using X-ray fluorescence spectrometry (Philips apparatus). They did not significantly differ from the compositions calculated from the weighed amounts of the starting materials.

For X-ray diffraction investigations $\left(\mathrm{CuK}_{\alpha}\right.$ radiation) two types of powder diffractometers (Philips) were used. An apparatus equipped with a graphite monochromator was employed for phase investigations (homogeneity, unit cell dimensions). Unit cell dimensions were determined using reflections in the region $60^{\circ}<2 \theta<120^{\circ}$.

Intensity measurements were carried out with an apparatus equipped with a Ni filter. Much attention was paid to the filling of the sample holder because the simple method of pressing the powder into the sample holder was found to give rise to deviations up to $25 \%$ between highest and lowest values of measured intensity ratios of certain reflections.

A random orientation of crystallites (small particles, loose packing) and uniform packing density in the surface layer are required in order to determine reproducibly accurate intensity ratios. The following procedure gave the best 
results. The crushed ceramics is mechanically ground and the fine powder obtained is then put into the flat sample holder via a sieve of hole diameter of $0.25 \mathrm{~mm}$. With the aid of a razor blade a flat surface is obtained. Intensity ratios are then measured at three different orientations of the sample holder (rotations of $120^{\circ}$ about the axis normal to the surface) with respect to the X-ray beam.

Dielectric properties of thin disks of dense samples (porosity $<5 \%$ ) were measured at various temperatures and frequencies using a Wayne-Kerr universal bridge (type B 221). The disks had been annealed during $36 \mathrm{~h}$ in oxygen to remove mechanical stresses and then provided with evaporated gold electrodes. The dc resistivity of these samples was beyond detection limit $(2 \times$ $\times 10^{8} \Omega \mathrm{cm}$ at room temperature and $5 \times 10^{7} \Omega \mathrm{cm}$ at $170^{\circ} \mathrm{C}$ ).

\section{Phase Investigations}

To get an idea of the shape of the homogeneity range of the perovskite phase in the system $\mathrm{SrO}-\mathrm{TiO}_{2}-\mathrm{La}_{2} \mathrm{O}_{3}$, samples of composition $x=0.133,0.25,0.30$, 0.35 , and 0.50 and various values of $\alpha$ were prepared. The study of the series of compounds with $x=0.30$ was most extensive. For this series the observed change of the unit cell dimension (a) with the number of moles $(y)$ of $\mathrm{SrO}$ present in excess compared with the composition with $\alpha=1.5(y=0)$ is shown in Fig. 1. A gradual increase of the parameter $a$ up to values well above the unit cell dimension of $\mathrm{SrTiO}_{3}(3.905 \mathrm{~A}[1])$, with increasing $\mathrm{SrO}$ content is found up to $y=0.18(\alpha=0.9)$. At still higher SrO content the parameter $a$ keeps constant, which indicates a two-phase region. This is confirmed by the observation of additional weak reflections of a second phase in the diffraction patterns for these compositions.

The series of compounds with $x=0.13$ and 0.25 also show an increase of the parameter $a$ with decreasing $\alpha$ (increasing $\mathrm{SrO}$ content) down to $\alpha \approx 1.0$. A sample of composition $x=0.35$ and $\alpha=1.00$ consisted of two or more phases, one of which was a perovskite phase, so that this composition lies outside the perovskite homogeneity range. From these results and from 'Tien and Hummel's work it can be concluded that the shape of homogeneity range (Fig. 2) is analogous to that found for the perovskite phase in the system $\mathrm{PbO}-\mathrm{TiO}_{\mathrm{s}}-\mathrm{La}_{2} \mathrm{O}_{3}$ which has been extensively studied [6]. Therefore, these results indicate that Tofield and Scott's [7] conclusion as to the absence of a range of non-stoichiometry of the perovskite phase in the system $\mathrm{SrO}-\mathrm{TiO}_{2}-\mathrm{La}_{2} \mathrm{O}_{3}$ is incorrect.

The diffraction pattern of a compound with $x=0.50$ and $\alpha=1.50$ which had been cooled slowly (during $4 \mathrm{~d}$ ) from 1300 to $800{ }^{\circ} \mathrm{C}$ and then quenched in air shows ten weak broad reflections with $d$-values of $7.79,3.48,2.59,1.88,1.70$, $1.55,1.44,1.35,1.27$, and $1.21 \AA$ in addition to the normal perovskite reflec-

Fig. 1. Unit cell dimension versus compositional parameter $y$ for $\mathrm{Sr}_{0.55+y} \mathrm{Laa}_{0.30} \mathrm{TiO}_{3+y}$. Some values of the compositional parameter $\alpha$ in the alternative formula $\mathrm{Sr}_{1-0.3 \alpha} \mathrm{La}_{0.30} \times \mathrm{TiO}_{3.45-0.3 \alpha}$ are indicated. The lengths of the symbols correspond to the uncertainties in the experimental values

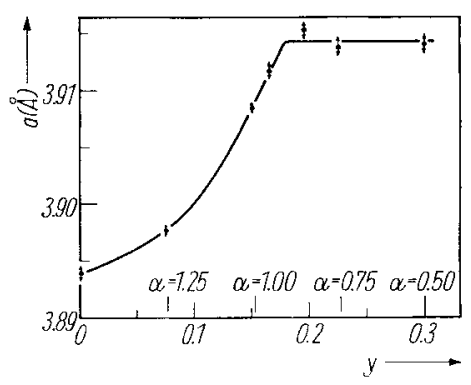




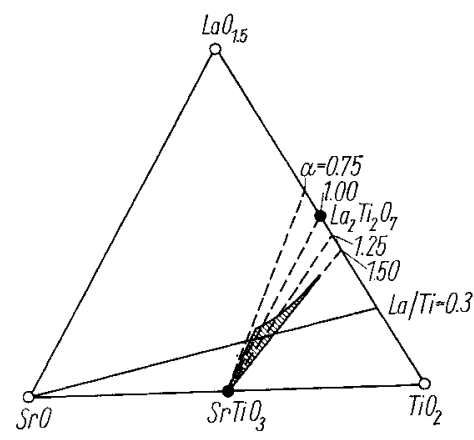

Fig. 2. Schematic phase diagram of the system $\mathrm{SrO}-\mathrm{TiO}_{2}-\mathrm{La}_{2} \mathrm{O}_{3}$. The shaded area corresponds to the homogeneity range of the perovskite-type phase in this system. Some lines of constant $\alpha$ and of constant La/Ti ratio are indicated

tions. These reflections were not observed for samples of the same composition which had been quenched from $1300{ }^{\circ} \mathrm{C}$ to room temperature. The $d$-values and the intensities of these weak reflections can be interpreted on the basis of a superstructure comparable to that proposed by Abe and Uchino [8] for $\mathrm{La}_{2 / 3} \mathrm{TiO}_{3}$ with interchanging A-site layers normal to the $c$-axis occupied by equal amounts of $\mathrm{Sr}$ (II) and La(III) ions in the one layer and equal numbers of La(III) ions and vacancies in the other. This gives rise to a tetragonal unit cell with $a=3.89$ and $c=7.78 \AA .^{3}$ )

The first three superstructure reflections have also been reported by Tien and Hummel [1] for a compound with $x=0.53$ and $\alpha=1.5$. They observed another weak reflection with $d=3.172 A$ which is not compatible with the tetragonal unit cell and which was neither observed in our work nor in Abe and Uchino's work. Probably this observation, as well as the intensities of some reflections reported by Tien and Hummel, is an erroneous result.

\section{Defect Structure}

The defects which may be present in this phase can be divided into two groups, depending on the probabilities that they are present.

To the first group of more probable defects belong defects of the type La and $V_{\mathrm{Sr}}^{\prime \prime}$. Due to the close agreement between the ionic radii of $\mathrm{Sr}$ (II) and La(III) ions it can be expected that La(III) ions have a strong preference for occupying $\mathrm{Sr}$ sites. Formation of vacancies at $\mathrm{Sr}$ sites looks the most probable way of compensating the excess positive charge which is a consequence of the incorporation of $\mathrm{La}(\mathrm{III})$ ions at $\mathrm{Sr}$ sites, because the occurrence of A-site vacancies in perovskites is very well known. Additional defects are necessary to account for the observed non-stoichiometry.

To the second group of less probable defects belong $\mathrm{La}_{\mathrm{Ti}}^{\prime}, \mathrm{V}_{\mathrm{Ti}}^{\prime \prime \prime}, \mathrm{V}_{\mathrm{O}}^{*}$, $\mathrm{Ti}_{\mathrm{Ti}}^{\prime}$, and interstitials. Because of the preparation conditions (sintering under oxygen at fairly low temperatures) used, and from the facts that negatively charged defects are necessary to compensate the excess positive charge due to La(III) ions and that the samples have fairly light colours (except samples with $\alpha=1.5$ ) we assume that the concentrations of $\mathrm{V}_{0}^{*}$ and $\mathrm{Ti}_{\mathrm{Ti}}^{\prime}$ are negligible. Magnetic susceptibility values did not indicate the presence of $\mathrm{Ti}(\mathrm{III})$. The presence of interstitials looks unrealistic in this well-filled structure. The presence of La ${ }_{\mathrm{Ti}}^{\prime}$ and $V_{T i}^{\prime \prime \prime}$ in small concentrations, although improbable, cannot be excluded.

$\left.{ }^{3}\right)$ The same superstructure has been found for the corresponding lead compound $\mathrm{Pb}_{0.25} \mathrm{La}_{0.50} \mathrm{TiO}_{3}[9]$. 
Kwestroo and Paping [10] found evidence that $\mathrm{Ca}$ (II) ions can be incorporated at $\mathrm{Ti}$ sites in the perovskite phase in the system $\mathrm{BaO}-\mathrm{CaO}-\mathrm{TiO}_{2}$. From luminescence measurements on $\mathrm{Sm}$ substituted $\mathrm{BaTiO}_{3}$ Murakami et al. [11] concluded that $\mathrm{Sm}$ (III) ions were present at Ti sites as well as at Ba sites. Unfortunately, neither paper proves that a significant number of such large ions (Ca, Sm) enters $\mathrm{Ti}$ sites. However, several complex perovskites (e.g. with two types of cation occupying B-sites) are known in which large ions occupy B-sites (e.g. see [12]).

The presence of $\mathrm{B}$-site vacancies in perovskites has only been reported for lanthana substituted $\mathrm{PbTiO}_{3}$ by Hennings and Rosenstein [13], and for lanthanum manganite by Tofield and Scott [7]. Again these conclusions were not based on convincing experimental results.

In the present work we have considered two extreme defect models with only three types of defects present in significant concentrations. In the first model (model I) $\mathrm{La}$ (III) ions are assumed to occupy exclusively $\mathrm{Sr}$ sites while vacancies are present at $\mathrm{Sr}$ and $\mathrm{Ti}$ sites. In the second model (model II) vacancies are assumed to be present at Sr sites only, while La(III) ions are distributed over $\mathrm{Sr}$ and $\mathrm{Ti}$ sites. For both models the numerical distribution of the defects is determined by composition $(x$ and $\alpha)$. For $\alpha=1.5$ the two models become identical to each other and to the defect structure proposed by Tien and Hummel [1]. As a third possibility (model III) a defect structure with four types of defects, viz. $\mathrm{La}_{\mathrm{Sr}}, V_{\mathrm{Sr}}^{\prime \prime}, \mathrm{La}_{\mathrm{Ti}}^{\prime}$, and $\mathrm{V}_{\mathrm{Ti}}^{\prime \prime \prime}$ is considered. In this model the defect concentrations are not uniquely determined by composition. They are intermediate between the defect concentrations for models I and II, however.

Diffraction patterns were calculated based on defect models I and II for compounds with $x=0.30$ and various values of $\alpha$. For these calculations atomic scattering factors for $\mathrm{Sr}(\mathrm{II})$, $\mathrm{La}(\mathrm{III})$, and $\mathrm{Ti}(\mathrm{IV})$ ions were taken from Cromer's compilation [14] and for oxygen 'ions Tokonami's results [15] were used. The scattering factors were corrected for the real part of the anomalous dispersion using the values reported by Cromer and Liberman [16]. Thermal motions of the atoms were allowed for by an overall isotropic temperature factor $B$. $B$-values between 0.5 and $1.2 \mathrm{~A}^{2}$ were used.

The intensity ratios of certain combinations of reflections, e.g. $I_{100} / I_{111}$, $I_{111} / I_{200}$, and $I_{311} / I_{222}$, have clearly different values for the two extreme models, whereas they have the same value for other combinations, e.g. $I_{290} / I_{110}$. This can be understood by considering the structure factors $F_{h k l}$ involved. $F_{h k l}$ can be one of the four types mentioned in Table 1. The three defect models considered dif-

Table 1

The four types of structure factor $F_{h k l}$ for perovskite $\left(\mathrm{ABO}_{3}\right)$ structures. $f_{\mathrm{A}}, f_{\mathrm{B}}$, and $f_{\mathrm{O}}$ are the scattering factors of $\mathrm{A}-, \mathrm{B}-$, and $\mathrm{O}$-sites, respectively

\begin{tabular}{c|c|c|c}
\cline { 2 - 4 } type & $\begin{array}{c}\text { number of } \\
\text { even indices }\end{array}$ & $\begin{array}{c}\text { number of } \\
\text { odd indices }\end{array}$ & $F_{h k l}$ \\
\hline 1 & 3 & - & $f_{\mathrm{A}}+f_{\mathrm{B}}+3 f_{\mathrm{O}}$ \\
2 & 2 & 1 & $f_{\mathrm{A}}-f_{\mathrm{B}}-f_{\mathrm{O}}$ \\
3 & 1 & 2 & $f_{\mathrm{A}}+f_{\mathrm{B}}-f_{\mathrm{O}}$ \\
4 & - & 3 & $f_{\mathrm{A}}-f_{\mathrm{B}}+3 f_{\mathrm{O}}$
\end{tabular}


fer only in the number of La(III) ions and vacancies at $\mathrm{Sr}$ and Ti sites, respectively (Table 2). This means that for those reflections, to which Sr and Ti sites

Table 2

Number of defects per unit cell for compounds of composition $x=0.30$ with $\alpha=1.50$ and 1.00 , respectively. The defect numbers of model III for $\alpha=1.00$ are intermediate

\begin{tabular}{c|c|c|c}
\hline $\begin{array}{c}\text { defect } \\
\text { type }\end{array}$ & $\begin{array}{c}\text { number } \\
(\alpha=1.50)\end{array}$ & \multicolumn{2}{|c}{$\begin{array}{c}\text { number } \\
(\alpha=1.00)\end{array}$} \\
\hline & & model I & model II \\
\hline $\mathrm{La}_{\mathrm{Sr}}^{\cdot}$ & 0.30 & 0.286 & 0.238 \\
$\mathrm{~V}_{\mathrm{Sr}}^{\prime \prime}$ & 0.15 & 0.048 & 0.095 \\
$\mathrm{La}_{\mathrm{Ti}}^{\prime \prime, i}$ & - & - & 0.048 \\
$\mathrm{~V}_{\mathrm{Ti}}^{\prime \prime}$ & - & 0.048 & -
\end{tabular}

contribute with the same sign, the $F_{h k l}$-values are independent of the model chosen. This is the case for reflections with $F_{h k l}$ of types 1 (e.g. 200) and 3 (e.g. 110). For well prepared specimens the experimental values of $I_{200} / I_{110}$ were in good agreement (within $3 \%$ ) with the values calculated.

Fig. 3 shows curves of calculated structure-sensitive intensity ratios against $\mathrm{SrO}$ content $(y)$ for the two extreme models. Variations of the temperature factor $B$ in the calculations leads to minor shifts of the curves parallel to themselves. Measured ratios are also shown in the figure. These are nearly independent of $y$. The agreement between measured and calculated curves is better for model II.

a

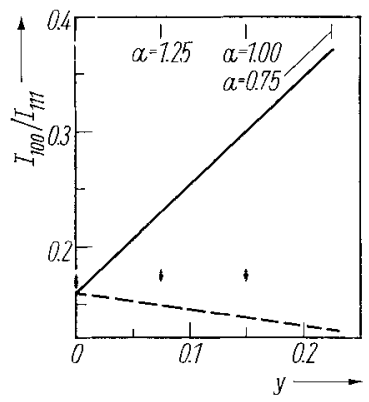

c

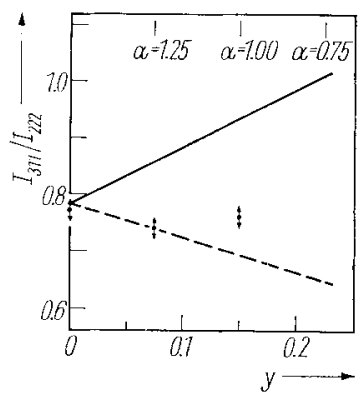

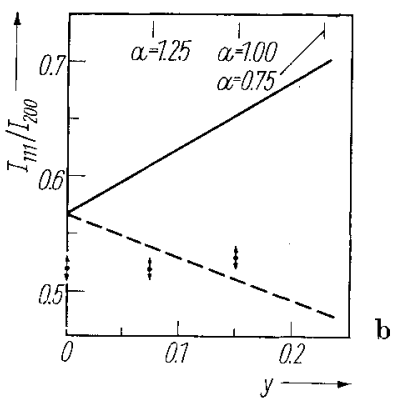

Fig. 3. Calculated (- model I; - - model II) intensity ratios versus compositional parameter $y$ (or $\alpha$ ) for compounds with $x=0.30$. a) $I_{100} / I_{111}$, b) $I_{111} / I_{200}$, and c) $I_{311} / I_{222}$. The experimentally determined values are indicated by symbols, the lengths of which correspond to the uncertainties 
Yet, the presence of B-site vacancies cannot be excluded. Therefore, model III with defect concentrations which are closer to the concentrations calculated for model II than those for model I (see Table 2) is most reasonable. The small differences in defect concentrations between the three models and the limited accuracy of the $\mathrm{X}$-ray method do not allow a more quantitative description of the defect structure based on X-ray diffraction results. Moreover, these models assume no interactions between point defects. However, due to the fairly high concentrations of the latter, such interactions look probable. Therefore, the real defect structure may be more complex.

Our recent $\mathrm{X}$-ray investigations on the defect structure of lanthana substituted $\mathrm{PbTiO}_{3}$ have led to roughly the same conclusions [6].

\section{Dielectric Relaxation}

Real $\left(\varepsilon^{\prime}\right)$ and imaginary $\left(\varepsilon^{\prime \prime}\right)$ parts of the dielectric constant of samples with compositions mentioned in Table 3 were measured in the temperature range

Table 3

Dielectric relaxation parameters of lanthana-substituted $\mathrm{SrTiO}_{3}$

\begin{tabular}{c|c|c|c|c|c|c|c}
\hline$x$ & $\alpha$ & $\begin{array}{c}T_{\varepsilon_{\max }^{\prime \prime}}^{\prime \prime} \\
\left({ }^{\circ} \mathrm{C}\right)\end{array}$ & $\left.\varepsilon_{\max }^{\prime \prime}{ }^{*}\right)$ & $\begin{array}{c}E_{\text {act }} \\
(\mathrm{eV})\end{array}$ & $\begin{array}{c}\tau_{0} \\
\left(10^{-13} \mathrm{~s}\right)\end{array}$ & $\begin{array}{c}\left.E_{\text {act }}{ }^{* *}\right) \\
(\mathrm{eV})\end{array}$ & $\begin{array}{c}\left.\tau_{0}^{* *}\right) \\
\left(10^{-13} \mathrm{~s}\right)\end{array}$ \\
\hline 0.133 & 1.50 & -58 & 440 & 0.33 & 17 & 0.31 & 7.55 \\
& 1.25 & -105 & 4000 & 0.31 & 2 & & \\
\hline 0.25 & 1.00 & -54 & 7800 & 0.40 & 4 & & \\
\hline 0.30 & 1.50 & -50 & 2300 & 0.33 & 22 & 0.38 & 0.49 \\
& 1.30 & -41 & 7600 & 0.38 & 5 & & \\
\hline 0.50 & 1.50 & -50 & 1600 & 0.43 & 8 & 0.39 & 0.78 \\
\hline \multirow{2}{*}{1.25} & -26 & 7200 & 0.31 & 4 & & \\
\hline
\end{tabular}

*) Measured at $2 \mathrm{kHz}$. **) Taken from [4]. ***) Disordered structure.

from -180 to $500{ }^{\circ} \mathrm{C}$ and at frequencies ranging from 0.5 to $2000 \mathrm{kHz}$. Two groups of relaxation phenomena were observed, one occurring below about $30{ }^{\circ} \mathrm{C}$ and the other above about $160{ }^{\circ} \mathrm{C}$. Only the low-temperature relaxation is discussed here.

Fig. 4. shows the temperature dependence of $\varepsilon^{\prime}$ and $\varepsilon^{\prime \prime}$ at 2 and $20 \mathrm{kHz}$, respectively, for a compound with $x=0.133$ and $\alpha=1.00 . \varepsilon^{\prime \prime}$ shows a maximum

Fig. 4. Real ( $O$ and $\bullet$ ) and imaginary ( $\Delta$ and $\Delta$ ) parts of the dielectric constant versus temperature for a compound with $x=0.133$ and $\alpha=1.00$ at 2 (open symbols) and 20 (closed symbols) $\mathrm{kHz}$, respectively

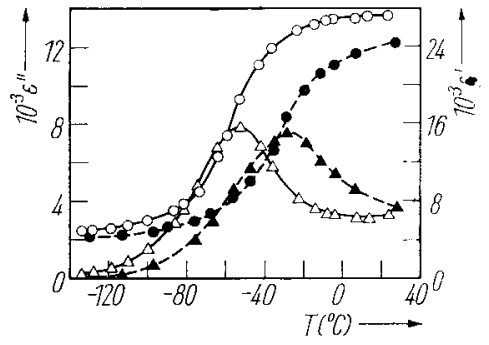


(relaxation peak) which shifts to higher temperature with increasing frequency. $\varepsilon^{\prime}$ changes considerably in the temperature region around the relaxation peak. 'The experimentally observed difference between the values of $\varepsilon$ ' on both sides of the relaxation peak is in agreement with the value calculated from the area under the peak in the $\varepsilon^{\prime \prime}$ versus frequency curve using the Kramers-Kronig relation [17]. This indicates that the change of $\varepsilon^{\prime}$ is indeed solely due to a relaxation process. Assuming that this relaxation is due to a thermally activated process, activation energy $\left(E_{\text {act }}\right)$ and relaxation time at high temperature $\left(\tau_{0}\right)$ were determined from plots of the Arrhenius-Boltzmann equation $\tau=$ $=\tau_{0} \exp \left(E_{\text {act }} / k T\right)$. Fig. 5 shows such plots for two compounds with $x=0.25$ and $\alpha=1.5$ and 1.3 , respectively.

Cole and Cole isotherms of $\varepsilon^{\prime \prime}$ versus $\varepsilon^{\prime}$ at various frequencies were determined. Fig. 6. shows such plots for two compounds with $x=0.133$ and $\alpha=1.50$ (a) and $1.00(\mathrm{~b})$, respectively. Their perfect semi-circular shape with their centres very elose to the $\varepsilon^{\prime}$-axis indicates that these relaxations are characterized by a very narrow distribution of relaxation times. Equally narrow distributions of relaxation times were observed for samples with $x=0.25$ and 0.30 , respectively, both with $\alpha=1.5$. Samples with $\alpha<1.5$ show a somewhat less symmetric distribution of relaxation times.

Table 3 shows the measured dielectric parameters of various samples. Some literature values [4] are included. No corrections for the small porosities were applied. Although the number of experimental data is restricted, some conclusions can be drawn yet. The relaxation parameters for compounds with $\alpha=1.5$ can be compared with those published earlier $[4,5]$. The maximum values of $\varepsilon^{\prime \prime}\left(\varepsilon_{\max }^{\prime \prime}\right)$ observed in our work are larger than those mentioned in $[4,5]$. This is probably caused by the narrower distribution of relaxation times found in our work. Our $E_{\text {act }}-$ and $\tau_{0}$-values agree well with the literature values $[4,5]$. Therefore, we assume that the same relaxation mechanisms play a role in these investigations.

From the fact that $E_{\text {act }}$ and $\tau_{0}$-values do not change much with variation of $x$ and $\alpha$, and that the distribution of relaxation times is narrow, it is concluded that the relaxation mechanism is the same for all compositions. The increase of $\varepsilon_{\max }^{\prime \prime}$ with decreasing $\alpha$ at fixed $x$ suggests that the number of relaxating units increases. The temperature at which $\varepsilon^{\prime \prime}$ reaches its maximum value $\left(T_{\varepsilon_{\max }^{\prime \prime}}^{\prime \prime}\right)$ increases with decreasing value of $\alpha$ at fixed frequency (except for the compound with $x=0.133$ and $\alpha=1.25$ ).

The dielectric properties of compounds with $x=0.50$ and $\alpha=1.5$ with ordered and disordered structure, respectively, are clearly different. The disordered compound behaves like the compounds mentioned above (Table 3 ). $\varepsilon^{\prime}$ of the ordered

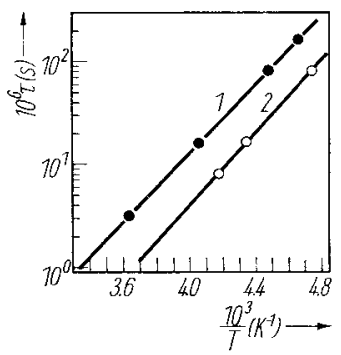

Fig. 5. Relaxation time versus reciprocal temperature for compounds with $x=0.25$ and $\alpha=1.50$ (1) and 1.30 (2), respectively 
Fig. 6. Cole and Cole plots for a) a compound with $x=0.133$ and $\alpha=1.50$ at $-8.3^{\circ} \mathrm{C}$; b) a compound with $x=0.133$ and $\alpha=1.00$ at $-19^{\circ} \mathrm{C}$. The frequencies $(\mathrm{kHz})$ at which the experimental points were determined are indicated
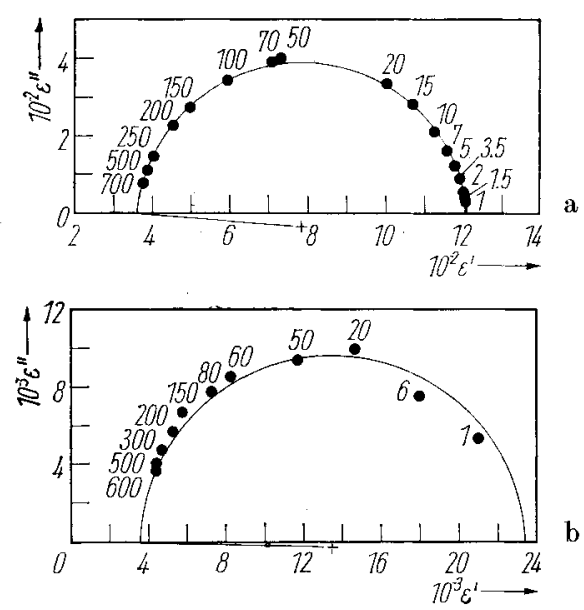

compound has a value of about 100 up to $300{ }^{\circ} \mathrm{C}$ and decreases very slowly with increasing temperature. $\varepsilon^{\prime \prime}$ of this compound is below detection limit up to about $230{ }^{\circ} \mathrm{C}$ and has a value of about 10 at $300^{\circ} \mathrm{C}$.

Relaxations of the type described here were completely absent in dense ceramic samples of pure $\mathrm{SrTiO}_{3}$. The relaxations in lanthana-substituted $\mathrm{SrTiO}_{3}$ originate from the highly defective nature of these compounds. From the measured relaxation parameters an ionic polarization mechanism must be preferred to an interfacial polarization mechanism. It is not sure whether the Skanavi (off-centre) model $[4,5]$ is the most acceptable model for the ionic polarization mechanism. From our X-ray diffraction investigations (Table 2 ) it was concluded that a decrease of $\alpha$ leads to a decreasing number of $\mathrm{Sr}$ site defects (La $\mathrm{L}_{\mathrm{Sr}}, \mathrm{V}_{\mathrm{Sr}}^{\prime \prime}$ ) and to an increasing number of Ti site defects $\left(\mathrm{La}_{\mathrm{Ti}}^{\prime}, \mathrm{V}_{\mathrm{Ti}}^{\prime \prime \prime}\right)$. Obviously the increasing number of $\mathrm{Ti}$ site defects or the number of associates between $\mathrm{Sr}$ site and $\mathrm{Ti}$ site defects is responsible for the increase of $\varepsilon_{\max }^{\prime \prime}$.

\section{Acknowledgement}

We thank Mr. B. J. Bongers for his valuable contribution to these investigations.

\section{References}

[1] T. Y. Tien and F. A. Hunmel, Trans. Brit. Ceram. Soc. 66, 233 (1969).

[2] J. Bouwma, Acta cryst. A31, S70 (1975).

[3] P. Ponta, F. S. Stone, and R. G. Turner, J. Solid State Chem. 11, 135 (1974).

[4] T. Y. Tien and L. E. Cross, Japan. J. appl. Phys. 6, 459 (1967).

[5] D. W. Johnson, I. E. Cross, and F. A. Hummel, J. appl. Phys. 41, 2828 (1970).

[6] K. J. de Vries, K. Keizer, J. Bouwma, and A. J. Burggraaf, Sci. Ceramics 8, 187 (1975).

[7] B. C. Tofield and W. R. Scott, J. Solid State Chem. 10, 183 (1974).

[8] M. A

[9] J. BovwмA, unpublished results.

[10] W. Kwestroo and H. A. M. Paping, J. Amer. Ceram. Soc. 42, 295 (1958).

[11] T. Murakami, T. Miyashita, M. Nakahara, and E. Sekine, J. Amer. Ceram. Soc. 56, 294 (1972).

19 physica (a) $35 / 1$ 
[12] F. S. Galasso, Structure, Properties, and Preparation of Perovskite-Type Compounds, Pergamon Press, 1969.

[13] D. Hennings and G. Rosenstein, Mater. Res. Bull. 7, 1505 (1972).

[14] D. T. Cromer and J. T. W ABER, Acta cryst. 18, 104 (1965).

[15] M. Tokonami, Acta eryst. 19, 486 (1965).

[16] D. T. Cromer and D. Liberman, J. chem. Phys. 53, 1891 (1970).

[17] V. V. Daniel, Dielectric Relaxation, Academic Press, 1967.

(Received January 15, 1976) 